\title{
A NEUROPHYSIOLOGICAL ASSESSMENT OF THE SURGICAL TREATMENT OF PERCEPTIVE DEAFNESS
}

\author{
Graeme M. Clark, Sydney, Australia
}

\section{Historical}

The results of treating patients with middle ear disease are now good, but the situation is not as satisfactory with perceptive deafness, and this is one of the major problems facing otologists today.

Various forms of electrical stimulation have been used during the last two centuries in the hope that total perceptive deafness could be corrected. From the first recorded attempt by Volta (1800), to the extensive studies by the Russians (Gersuni and Volokhov, 1936) and the detailed work by Jones, Stevens and Lurie (1940) the research workers have all endeavoured to stimulate hearing electrically with electrodes placed outside the cochlea. The auditory sensation was usually very clear and speech could be understood. These results, however, were only obtained in patients with normal or some residual hearing. It became evident that in many cases electrical energy was transduced into sound vibrations before it reached the inner ear. Work was done by Jones et al. (1940) which established this fact, and hearing induced in this way has been called the electrophonic effect.

Their study indicated that there were three mechanisms which produced hearing when the cochlea was stimulated electrically. Firstly, the middle ear could act as a transducer and convert alterations in the strength of an electrical field into the mechanical vibrations which produce sound. It was thought that the tympanic membrane would be attracted to and from the medial wall of the middle ear, and that these vibrations were responsible for the hearing sensation. Sound could also be heard, however, when the middle ear structures were absent, and the authors demonstrated a second type of transducer. They suggested that electrical energy could be converted into sound by a direct effect on the basilar membrane, which would then vibrate maximally at a point determined by the frequency, and these vibrations would stimulate the hair cells. Thirdly, a crude hearing sensation was produced in patients with minimal hearing, and this was probably due to direct stimulation of the auditory nerve.

These conclusions are still basically correct, although more detailed work has been done on the subject. Flottorp (1953) has shown that the skin over any part of the body can act as a transducer so that hearing is then produced by air or bone conduction. This means that the middle ear need not be the only transducer of sound as postulated by Jones et al. (1940), but that the skin lining the external auditory meatus and overlying the mastoid could act equally well. 
During this research into electrophonic hearing, it became apparent that total perceptive deafness could not be corrected by inducing a widespread electrical field in the region of the cochlea, but that more localized stimulation of the auditory nerve fibres was required. One of the earliest attempts to stimulate the auditory nerve was by Lundberg in 1950 (reported by Gisselsson, 1950). He stimulated the auditory nerve during a neurosurgical operation, but the patient could only experience noise.

A more detailed study was performed by Djourno and Eyriès (1957), and the stimulus parameters appear to have been well controlled. In their patient, the electrode was placed on the auditory nerve, which was exposed during an operation for cholesteatoma. The patient was able to appreciate differences in pitch of up to a frequency of 1000 pulses per second, and the difference limen for frequency was about 100 pulses per second. With instruction, the patient was also able to distinguish certain words, such as "papa", "maman" and "allô".

It appeared from these studies that electrical stimulation of the auditory nerve could not reproduce most of the frequencies required by speech discrimination, and that the refractory period of a nerve would put an upper limit of 1000 pulses per second on the rate of maximum stimulation. Consequently, it seemed more logical to stimulate the terminal fibres of the auditory nerve in the cochlea, so that hearing could possibly be produced in accordance with the place principle.

This was performed by Simmons, Epley, Lummis, Guttman, Frishkopf, Harman and Zwicker (1965) who gave a detailed account of varying the stimulus parameters in a patient who had six electrodes implanted in the modiolus of the cochlea. The patient could only perceive pitch up to a frequency of 300 pulses per second in spite of the fact that the stimulus wave shape and rate of presentation were varied. Speech was also separated into different frequency bands and these were used to stimulate the appropriate electrodes. but speech discrimination remained poor.

This study by Simmons et al. (1965) appears to have been well controlled, and indicates that there are still many problems that must be solved before adequate hearing can be produced by stimulating the auditory nerve. These problems are not just limited to the auditory system, but affect the general somatic sensory system as well (Frank, 1968) where the difficulties are also great but not without solution.

One of the main problems associated with electrical excitation of the auditory system is whether it is better to stimulate the auditory nerve in accordance with the volley theory or the place theory of frequency perception (Wever, 1951). Recent work by Rose, Brugge, Anderson and Hind (1967) supports the volley theory of frequency coding, and has shown that the auditory nerve fibres of the squirrel monkey can respond in phase to frequencies up to $5.0 \mathrm{kHz}$.

This means that in response to a $5.0 \mathrm{kHz}$ tone, an auditory nerve fibre could fire every fifth cycle of the stimulus at a constant phase of the sine wave. If we consider a large population of nerve fibres responding to a $5.0 \mathrm{kHz}$ tone, then some will fire every cycle.

Consequently, if the auditory nerve is to be stimulated in accordance with the volley theory, an electrical stimulus must be found which will cause the nerve 
cells to fire in phase, but not necessarily with each cycle, so that a response to high rates of stimulation can be obtained.

On the other hand, the auditory system may be stimulated in accordance with the place theory in a manner similar to that used by Simmons et al. (1965). If the brain codes frequency in this way, then advances in electrode design will be required to prevent damage to the terminal fibres of the auditory nerve, as this could lead to retrograde degeneration of this nerve, and transsynaptic degeneration in the cochlear nucleus and higher order relay centres.

\section{Neurophysiology}

In a recent study (Clark, 1969; Clark and Dunlop, 1968, 1969) I have performed experiments on cats in an attempt to see whether neurophysiological techniques would help decide which method of electrical stimulation of the auditory system should be used. In these experiments the auditory nerve and the cochlea were stimulated electrically, and the poststimulus histograms of their firing patterns recorded from cells in the superior olivary complex, a second order relay nucleus in the brain. These were compared with the poststimulus histograms obtained from the same cell in response to an auditory stimulus.

The poststimulus histogram is a common way of analysing the pattern of nerve discharge, and is obtained by measuring the time of occurrence of each nerve discharge after the auditory stimulus. The summed responses of the time delays of the discharge can then be plotted as a histogram. The construction of a poststimulus histogram is illustrated by the diagram in Figure 1 (Clark, 1968). The vertical strokes indicate nerve discharges and the

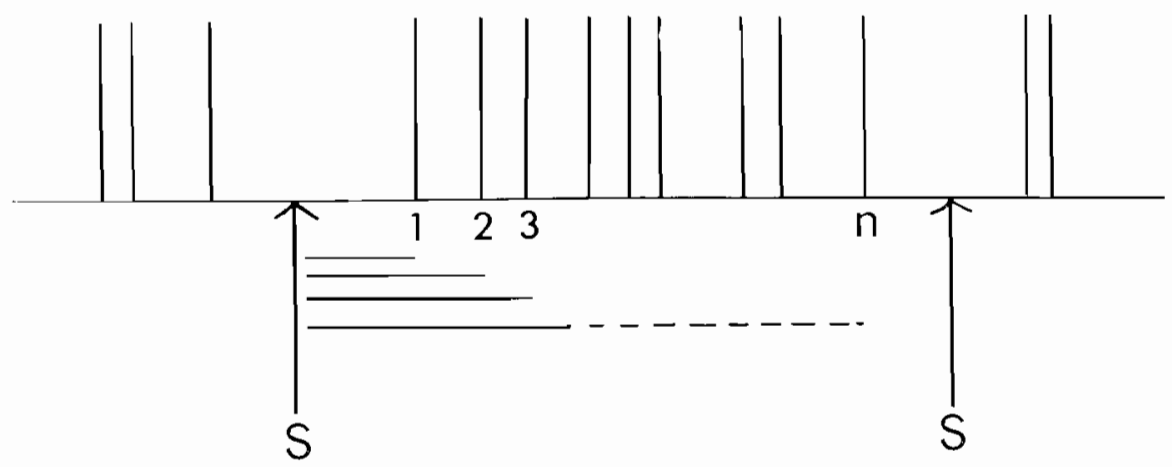

Figure 1. A diagram of the method of constructing a poststimulus histogram.

arrows marked $S$ are the points of acoustic stimulation. The type of coding described measures the time from the stimulus $S$ to nerve discharges $1,2,3$, etc. over a number of stimuli. The frequency with which these time intervals occur over a number of stimuli is then plotted as a poststimulus histogram as shown in Figure 2. Here, the ordinate refers to the probability of a cell firing and the abscissa to the interval of time after acoustic stimulation at which nerve discharges occur. 


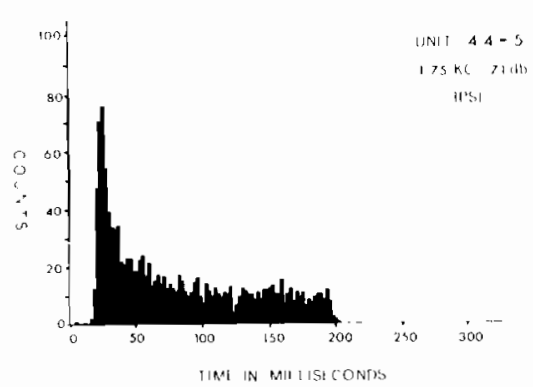

A

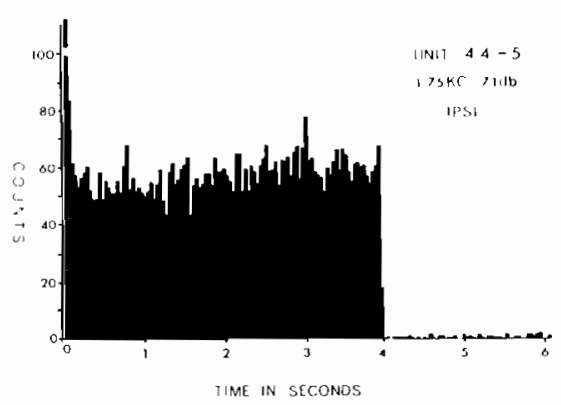

B

Figure 2. Poststimulus histograms.

The poststimulus histogram was chosen as a measure of the efficacy of an electrical stimulus in reproducing the natural stimulus. This does not mean that if an electrical stimulus does not reproduce this pattern, it would be unsatisfactory, as the central nervous system has developed the ability to generalise and disregard a lot of sensory information. Nevertheless, without any other criteria this should provide a rigid standard in measuring the performance of electrical stimulation.

The results of this study showed the electrical stimulation of the auditory nerve as a whole, at different rates, could not reproduce the same firing patterns as a sound having the same frequency. However, it was possible to stimulate a nerve cell at rates less than 200-300 per second, and the reason higher rates could not be obtained was probably due to the fact that the electrical stimulus produced synchronous firing of all the auditory nerve fibres, and that the inhibitory mechanisms in the cochlear nucleus prevented more rapid stimulation.

An example of the failure of an electrical stimulus to reproduce in a cell the same firing pattern as sound, can be seen in Figure $3 A$ and $B$. In Figure $3 A$ the action potentials fire in a burst in response to a tone pulse of $700 \mathrm{~Hz}$, but in Figure $3 \mathrm{~B}$ an electrical stimulus of the same rate and duration produces no response, and the cell continues to fire in a random fashion.

These results are for a relatively small number of cells and do not indicate the findings that would possibly have been obtained if the whole population of cells in one animal had been tested by acoustic stimulation of the ear, and electrical stimulation of the auditory nerve. Consequently, a study was undertaken on the effects of different rates of electrical stimulation of the auditory nerve on the amplitudes of the field potentials recorded from the superior olivary complex. The field potentials are the summed electrical activity of many cellular action potentials, and are an indication of the responses of a large number of cells.

In four cats the auditory nerve was stimulated with $0.1 \mathrm{msec}$ electrical square waves at rates of $1,50,100,200,300$ and 500 per second. The evoked potentials recorded in the superior olivary complex were photographed on the cathoderay oscilloscope display, and their peak-to-peak amplitudes measured and averaged for each frequency tested. In one case, a marked reduction in the amplitude of the field potential occurred at stimulus rates of 50 per second, but 

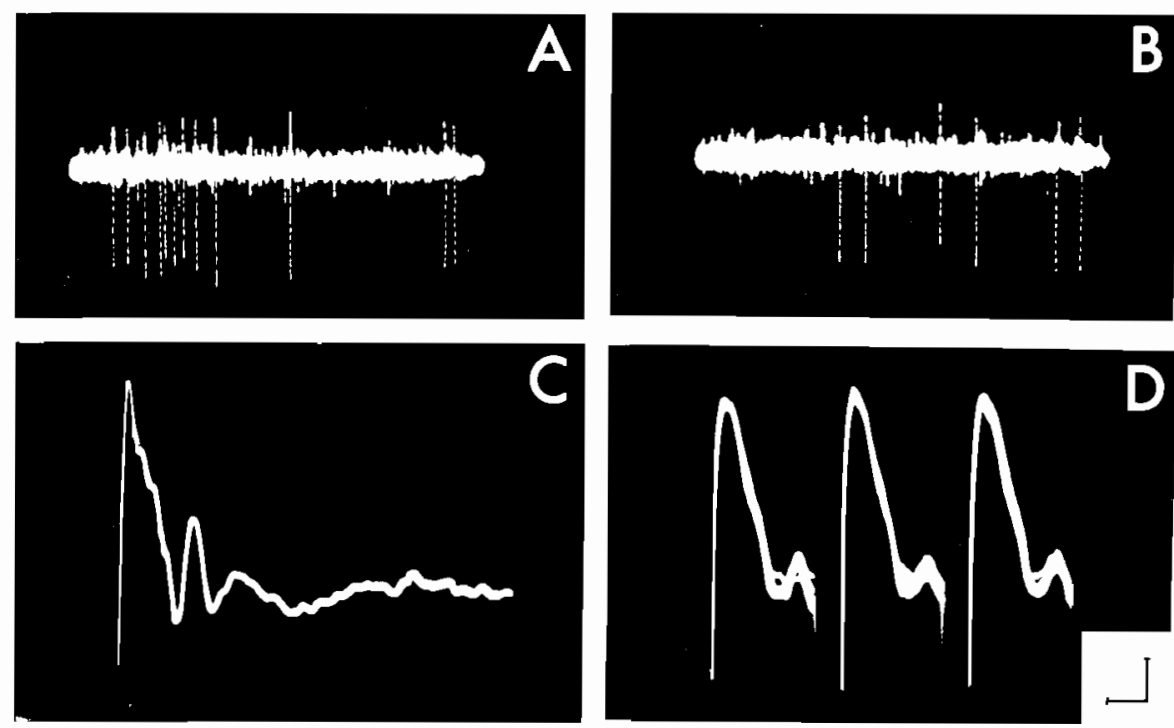

Figure 3. Cellular activity and field potentials recorded from the superior olivary complex of the cat. Cellular findings:

A. $700 \mathrm{~Hz}$ tone

B. 700 puise per second electrical stimulus of the auditory nerve

Field potentials:

C. 1 per second electrical stimulus of the auditory nerve.

D. 300 per second electrical stimulus of the auditory nerve.

Calibration:

A. B. Horizontal bar - 20 msec; vertical bar - $200, \mathrm{~V}$

C. D. Horizontal bar - $1 \mathrm{msec}$; vertical bar - $50 " \mathrm{~V}$

All recordings were made with a monopolar electrode with ground as the reference An upward deflection is positive.

in the others a reduction only occurred when rates of 200-300 per second were used (Figure $3 \mathrm{C}$ and $\mathrm{D}$ ).

Consequently, this neurophysiological study confirms the clinical finding that standard forms of electrical stimulation will not produce frequency discrimination above about $300 \mathrm{~Hz}$. If the volley theory is to be the basis of electrical stimulation of the auditory nerve, then a different form of electrical stimulation must be used

Finally, the cochlea was stimulated electrically in accordance with the place theory by electrodes placed on its surface. It was found that the cells in the superior olivary complex would respond to high frequency but not low frequency stimulation. This suggests that the electrical field could reach the basal, but was not strong enough to excite the more distant apical region of the cochlea. It follows that electrode design must be improved so that an intimate connection can be made with many nerve fibres without damaging them. In summary, the neurophysiological evidence indicates that, if perceptive deafness is to be treated surgically, electrical stimulation in accordance with the place theory is more likely to be successful. This work has also shown that the experimental animal can be used to test different electrode systems, 
and provides good evidence of how effective they are in reproducing sound. During the developmental stage this will reduce the necessity of operations on patients

\section{SUMMARY}

The historical development of the various possible methods of producing hearing by electrical stimulation of the auditory system has been discussed. This survey indicates that direct stimulation of the auditory nerve is capable of producing sound, but at the moment the discrimination of frequencies above $300 \mathrm{~Hz}$ is not good.

Consequently, a neurophysiological study has been undertaken to determine which method of stimulating the auditory system electrically has the greatest chance of reproducing the effects of sound. The auditory nerve and internal ear of the cat have been stimulated electrically at different frequencies, and the effects on cell firing responses in the superior olivary nucleus have been compared with those obtained by stimulating the auditory system with sound of the same frequency.

The results show that the greatest chance of success is obtained by electrical stimulation of the inner ear, with the electrodes placed close to the terminal fibres of the auditory nerve. The experimental animal has also been very useful in examining different types of electrode systems before their use in treating patients.

\section{RÉSUMÉ}

Après avoir passé en revue les différentes méthodes susceptibles de produire une sensation d'audition par stimulation auditive, nous pouvons dire qu'une stimulation directe du nerf auditif est capable de produire un son, mais actuellement une discrimination des fréquences au dessous de $300 \mathrm{~Hz}$ n'est pas bonne.

Aussi nous avons entrepris une étude neuro-physiologique chez le chat pour déterminer une meilleure méthode. La plus grande chance de succès est obtenue lors de la stimulation électrique de l'oreille interne avec des électrodes sur ies fibres terminales du nerf auditif. L'expérimentation sur l'animal a été très utile pour l'essai de différents systèmes d'électrodes avant leur emploi pour des malades en traitement.

\section{REFERENCES}

1. Clark, G. M., 1968: The coding of sound in the auditory system. J. acoust. Soc Aust., 2, 19-24.

2. Clark, G. M. 1969: Responses of cells in the superior olivary complex of the cat to electrical stimulation of the auditory nerve Exp. Neurol., 24, 124-136.

3. Clark, G. M. and Dunlop, C. W. 1968: Field potentials in the cat medial superior olive. Exp. Neurol., 20, 31-42.

4. Clark, G. M. and Duniop, C.W. 1969: Poststimulus time response patterns in the nuclei of the cat superior olivary complex. Exp. Neurol., 23, 266-290.

5. Djourno, A., Eyriès, C and Valencien, 1957: Prosthése auditive par excitation électrique à distance du nerf sensoriel à l'arde d'un bobinage inclus à demeure. Presse Med. $35,14.17$

6. Flottorp, G., 1953: Effect of different types of electrodes in electrophonic hearing 1. acoust. Soc. Amer., 25, 236-245. 
7. Frank, K., 1968: Some approaches to the technical problem of chronic excitation of peripheral nerve. Ann. Otol. (St. Louis), 77, 761-772.

8. Gersuni, G. V. and Volokhov, A. A., 1936: On the electrical excitability of the auditory organ: On the effect of alternating currents on the normal auditory apparatus. J. exp. Psychol., 19, 370-382.

9. Gisselsson, L., 1950: Experimental investigation into the problem of humoral transmission in the cochlea. Acta oto-laryng. Suppl., 82, 16.

10. Jones, R. C., Stevens, S. S. and Lurie, M. H., 1940: Three mechanisms of hearing by electrical stimulation. J. acoust. Soc. Amer., 12, 281-290.

11. Rose, J. E., Brugge, J. F., Anderson, D. J. and Hind, I. E., 1967: Phaselocked response to low-frequency tones in singie auditory nerve fibers of the squirrel monkey. J. Neurophysiol., 30, 769-793.

12. Simmons, F. B., Epley, J. M., Lummis, R. C., Guttman, N., Frishkopf, L. S., Harmon, L. D. and Zwicker, E., 1965: Auditory nerve: Electrical stimulation in man. Science. $148,104-106$

13. Voita, A., 1800: On the electricity excited by mere contact of conducting substances of different kinds. Roy. Soc. Phil. Trans., 90, 403-431.

14. Wever, E. G., 1951: Theory of hearing. John Wiley and Sons Inc., New York, 43-75.

Brain Research Unit, Department of Physiology, University of Sydney, N.S.W., Australia.

The National Health and Medical Research Council of Australıa provided funds for this research.

My thanks to Assoc. Prof. C. W. Dunlop for his support and interest in this study. I would like to thank Miss J. Harvey for technical assistance, Mr. E. Foster for photographic help and Miss R. Swan for the typing. 


\section{University Library}

\section{- M M N E R VA A gateway to Melbourne's research publications}

Minerva Access is the Institutional Repository of The University of Melbourne

Author/s:

Clark, Graeme M.

Title:

A neurophysiological assessment of the surgical treatment of perceptive deafness

Date:

1970

Citation:

Clark, G. M. (1970). A neurophysiological assessment of the surgical treatment of perceptive deafness. International Journal of Audiology, 9(1), 103-109.

Persistent Link:

http://hdl.handle.net/11343/27118 